\title{
Longer duration of exclusive breastfeeding reduces maternal weight retention: results from the CLaB study
}

Michelly da Silva Alves 1

https://orcid.org/0000-0002-3827-212X

Maiara Aparecida Mialich Almeida 2

(iD) https://orcid.org/0000-0002-0641-0743

Caroline de Barros Gomes 3

https://orcid.org/0000-0002-9576-4251

Anna Paula Ferrari 4

https://orcid.org/0000-0002-5370-4349

Cristina Maria Garcia de Lima Parada 5

https://orcid.org/0000-0002-9597-3635
Maria Antonieta de Barros Leite Carvalhaes 6

(iD) https://orcid.org/0000-0002-6695-0792

\footnotetext{
1,2 Programa de Pós-graduação em Enfermagem. Faculdade de Medicina de Botucatu.Universidade Estadual Paulista "Julio de Mesquita Filho". Botucatu, SP, Brasil. 3,4 Programa de Pós-graduação em Saúde Coletiva. Faculdade de Medicina de Botucatu. Universidade Estadual Paulista "Julio de Mesquita Filho". Botucatu, SP, Brasil.

5,6 Departamento de Enfermagem. Faculdade de Medicina de Botucatu. Universidade Estadual Paulista "Julio de Mesquita Filho" Campus de Rubião Júnior, s.n. Botucatu, SP, Brasil. CEP: 18.618-687. E-mail: maria.carvalhaes@unesp.br
}

\begin{abstract}
Objectives: to evaluate the relation between breastfeeding and postpartum weight retention.

Methods: this prospective cohort study involved 641 newborns and their mothers, followed up to twelve months postpartum. Data were collected from June 2015 to February 2017. In the first interview, we investigated data regarding socioeconomic and demographic characteristics, obstetric history, weight, and gestational age of the infant at birth. Maternal weight and breastfeeding status were obtained at 3, 6, 9 and 12 months postpartum at the mother's home. A descriptive analysis of maternal weight retention according to the lactation status was performed. Multiple linear regression models evaluated the effect on exclusive breastfeeding and total breastfeeding duration on maternal weight retention at 6 and 12 months postpartum, considering potential confounders.

Results: 512 and 490 mothers were evaluated at six months and at twelve months postpartum, and the mean weight retention was $1.79(S D=5.52)$ and $1.69(S D=6.69) \mathrm{kg}$, respectively. Regardless of the confounders, the mean postpartum weight reduction for each day of exclusive breastfeeding was 11 (CI95\% $=-0.019$ to -0.003$)$ and 16 grams $(C 195 \%=-0.026$ to -0.007) for 6 and 12 months, respectively. The total maternal breastfeeding duration had the same effect.

Conclusions: longer periods of exclusive breastfeeding and total breastfeeding are associated with lower postpartum weight retention.
\end{abstract}

Key words Maternal Breastfeeding, Infant, Prenatal care, Body weight, Epidemiology

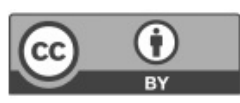




\section{Introduction}

In both rich and poor countries, women at childbearing age or those who had a pregnancy have shown increased adiposity, so the relation between obesity and the women's reproductive life has become a topic of priority for researchers and public health managers. ${ }^{1}$ In obesogenic contexts such as those which prevails in much of the world 2 and also in Brazil, ${ }^{3}$ pregnancy has been noticed as a potential risk factor for obesity 4 and chronic-degenerative diseases in women as well as in their children, when they reach adulthood. 5

Excessive gestational weight gain and postpartum weight retention are both nutritional events related to the reproduction which increase the risk of obesity in women, 6 the latter being the focus in the present study. Weight retention is the positive difference between a patient's maternal weight at some moment after delivery and their pre-gestational weight. Its negative effects have been identified, such as the fact that women with normal weight who become overweight or obese after pregnancy are more likely to have complications in subsequent pregnancies. ${ }^{1}$ Even a relatively small increase of one to two units in a patient's Body Mass Index (BMI) after pregnancy increases the chances of gestational diabetes and hypertensive disease in subsequent pregnancies, even for women who are not overweight or obese. 7 Thus, understanding the magnitude of postpartum weight retention and its determinants in a population is relevant and necessary knowledge to define health actions aimed to prevent female obesity and pregnancy complications.

It is known that postpartum weight retention is influenced by a complex network of interrelationships, which includes everything from socioeconomic and lifestyle factors, parity, gestational weight gain and the woman's nutritional status at the beginning of the pregnancy. ${ }^{8-11}$

The effects of breastfeeding duration and intensity on postpartum weight retention are still controversial, but plausible according to the physiology of the pregnancy and lactation. The evidence produced so far has presented contradictory results, preventing a conclusion on this topic, as shown by a systematic review that included 28 studies, most of which were produced in the United States. ${ }^{9}$ Subsequent studies failed to resolve the issue, indicating that the effects maybe different depending on the context. For instance, there was no significant association between weight retention in the first three months of postpartum and exclusive breastfeeding in Porto Alegre, a city in the South of Brazil.10 Furthermore, an inverse association was detected between weight retention and the duration of exclusive breastfeeding in another city in the South of Brazil. 12

In another Brazilian cohort study carried out in São Luís, in the State of Maranhão, in the Northeast of Brazil, the duration of breastfeeding had a direct negative effect on postpartum weight retention but on a smaller scale. After adjusting for confounders, an increase of one standard deviation in the duration of breastfeeding corresponded to a decrease of 0.10 on the standard deviation in postpartum weight retention. 13

Divergent results were also reported at an international level. In an American study was carried out with 441 postpartum women, at six weeks and twelve months after the infant's birth, it demonstrated that mothers who practiced artificial breastfeeding lost more weight than those who breastfed until six weeks after delivery. At twelve months, the type of breastfeeding did not affect weight loss. ${ }^{14}$ In Australia, 2231 women were followed up from pregnancy to twelve months postpartum, and it was observed that breastfeeding for three months or more reduced the chance of weight retention in the highest quintile $(\mathrm{OR}=0.673(\mathrm{CI}=0.471-0.961) .15$

In both Brazilian and international studies, analyses were adjusted for possible confounders. In all of them, gestational weight gain, pre-gestational BMI, parity, and socioeconomic variables were considered. In two studies, 10,13 adjustments were also made on caloric intake, since breastfeeding can influence maternal weight retention precisely because it affects both the mother's caloric consumption and expenditure. In addition to the divergent results and the adjustment of the effect by different variables, there is a risk of memory bias in some previous studies because the data collection on the duration of breastfeeding was carried out after a long interrupted period. All of this justifies further studies, especially prospective studies with frequent data collection and information on many of the potential confounders, such as the one presented in this article.

The aim of this study was to examine the relation between breastfeeding duration and postpartum weight retention based on data from a cohort of mothers and their children, assessed over the infants' first year of life. The tested hypothesis was that the longer the duration of exclusive breastfeeding in the first six months and the longer the duration of total breastfeeding in the first year of life, the lower the maternal weight retention at six and twelve months postpartum. 


\section{Methods}

The data are taken from the Coorte de Lactentes de Botucatu (CLaB) (Infant Cohort study in Botucatu), carried out from 2015 to 2017, whose main objective was to know the health situation of the infants and their determinants in the first year of life in the city of Botucatu (State of São Paulo, Brazil). The original study is a prospective, population-based cohort study, with the mothers and their live newborns from June 29, 2015, to January 11, 2016.

All mother/newborn pairs who met the inclusion criteria (newborns up to 30 days old living in the city whose mothers were able to respond face-to-face and telephone interviews) were invited to participate. All mothers who agreed to take part in the study signed an informed consent form (Ethics Committee at Faculdade de Medicina in Botucatu - CAAE document number: 67214217.5.0000.5411).

Botucatu is a city in the countryside of São Paulo, in the Southeast region of Brazil, with an estimated population of 141,032 inhabitants in 2017, a birth rate of 12.8 per 1,000 inhabitants and an infant mortality rate of 12.7 per 1,000 live births. 16 In relation to maternal and child care services, the city has two hospitals (one public and one private) where there are maternity beds, a network of 20 public primary healthcare units and several other private offices, in addition to two emergency rooms, one public and the other private. There is also a Núcleo de Apoio à Saúde da Família (NASF) (Family Health Support Center) where physicians, nutritionists, psychologists, physical educators, and other health professionals work, supporting and carrying out interprofessional and intersectoral actions together along with the primary care unit network. ${ }^{17}$

The city also has a health unit called Clinica do Bebê (CB) (Baby Clinic), a neonatal, program-based public service that provides for all newborns in the city, both, those born in public and private maternities, with their first appointment with a pediatrician and a pediatric nurse, as well as carrying out mandatory neonatal screening are mandatory in Brazil. The scheduling for the first consultation and exams is done at the maternity before hospital discharge of the mother/child pairs and this occurs before the infant is two weeks old. 17

As the Clínica do Bebê has a high population coverage rate, close to $90 \%, 19$ it was elected as the place to recruit mothers and infants to form the CLaB study cohort. In the recruiting period of participants for the cohort, there were 1,055 births registered in the city of Botucatu and 923 mother/child pairs received care at the Clínica do Bebê. The inclu- sion criteria for newborns to take part in the $\mathrm{CLaB}$ study were: younger than 30 days old and have mothers who were able to respond face-to-face and telephone interviews and who were residents inthe urban area of the city. 656 infants and 650 mothers were included in the cohort. The study excluded twins $(n=12)$ and their mothers $(n=6)$, an infant with a congenital oral cavity defect (1), a mother who was HIV-positive (1) and a mother who had undergone a mastectomy (1), as for, these conditions make breastfeeding difficult or inadvisable. Therefore, the cohort analyzed in the present study was composed, at the initial moment or baseline, by 641 mother/newborn pairs.

Data collection occurred from July 27, 2015, to February 2, 2017. In the present study, data collected were used in the following moments: before the newborn's first clinical consultation at the Clínica do Bebê; at 3, 6, 9 and 12 months of age at home.

At the Clínica do Bebê, mothers' socioeconomic and demographic information, obstetric history, type of delivery, weight and gestational age at birth were collected. Pre-gestational maternal weight was also obtained by consulting the prenatal care card and measuring maternal height, for later calculation of pre-gestational BMI. Mothers were interviewed at home when their children were 3, 6,9 and 12 months old. On this occasion, mothers answered a questionnaire on the infant's feeding. The infant's weight and height and the mother's weight were also measured. The mothers' weight was measured in a single measurement at each visit by the interviewers trained in anthropometry. A digital scale, Bioland model EB9010 plus, with a $150 \mathrm{~kg}$ capacity, was used with a graduation of 100 grams. Mothers were weighed wearing light clothes and barefoot, following the Brazilian anthropometric measurement recommendations. ${ }^{18}$ At six and twelve months postpartum, maternal eating practices and exercises were also evaluated.

Weight retention in each postpartum period was calculated by subtracting the measured maternal weight from the pre-pregnancy weight. This calculation was performed with maternal weight data obtained at the 3, 6, 9 and 12 months visits. In the absence of information on pre-gestational weight, or in the case of inconsistency (difference greater than $2 \mathrm{~kg}$ between the pre-gestational weight and the first weight measured in a prenatal consultation held in the first gestational trimester, 19,20 ) the first maternal weight measured in prenatal care was used as the initial weight, provided that it was obtained before fourteen weeks of gestational age. These data were used to describe the evolution of maternal weight 
retention in the first postpartum year and to compare the mean values according to the infant's breastfeeding situation.

In order to investigate the influence on the duration of exclusive breastfeeding (EBF) and total breastfeeding (BF), only weight retention values at 6 and 12 months of age were taken as outcomes. This option was taken into account that six months is the indicated period of exclusive breastfeeding and that, in the case of this study, twelve months was the age of completion of the cohort follow-up.

The duration of EBF (days) and BF (days) were tested exposure factors. EBF was considered to be the period during which infants were fed exclusively with breast milk, directly from the breast or pumped, including breast milk from a milk bank, without any other liquid or solid food. However, infants could be given drops or syrups containing vitamins, minerals, and medications. BF was considered as a period during which infants were fed with breast milk, regardless of whether they were given other liquids, such as tea, water, juices, formulas, cow's milk or solid foods of any kind. 21

Thus, the duration of EBF was defined as the infant's age, in days, when the first food other than breast milk was introduced and the duration of $\mathrm{BF}$ as the child's age, in days, when breastfeeding ceased completely.

In order to define the infant's breastfeeding situation, each interview contained questions on whether the baby was breastfeeding (yes or no) and whether each of a list of 48 food items had been introduced into the infant's diet (yes or no). This list was developed by the researchers based on recommendations from the Brazilian Ministry of Health 22 and a food survey with infants was carried out in the city. 23 Among the food surveyed are: non-breast milk (formula, liquid or powdered cow's milk and other milk), water/teas/natural juices/artificial juices/other drinks (yes or no for each) and solid foods such as fruit, cereals, flour, vegetables, meat, and among others (yes or no for each), so that the infant's situation in relation to $\mathrm{EBF}$ and $\mathrm{BF}$ at each moment could be defined. In addition, when mothers stated they had introduced a food item other than breast milk into an infant's diet, the researchers inquired about the date of introduction and whether and when breastfeeding had ceased.

To characterize the cohort and identify potential confounders in the association between breastfeeding and breast weight retention, several covariables were investigated: maternal age at birth (in years, categorized as $\leq 19,20-34$ and $\geq 35$ years); parity (primiparous, multiparous); type of delivery (cesarean or vaginal delivery); pre-gestational nutritional status (normal weight, low weight, overweight, obesity), assessed from pre-gestational BMI; adequacy of gestational weight gain (in $\mathrm{Kg}$, obtained by the difference between pre-gestational weight and weight measured in the last prenatal appointment, and subsequently categorized as adequate, insufficient and excessive, according to the Institute of Medicine (IOM) standards, a reference that takes gestational age into account 24; maternal schooling and categorized (as $\leq 8,9-11, \geq 12$ years); selfreported skin color (categorized as white, mixed race, black and other, subsequently dichotomized into white, non-white); paid maternal work outside the home (yes or no); mother lives with a partner (yes, no); mother exercised regularly in the three months prior to the interview, measured at six and twelve months postpartum with the question: "in the last three months, did you exercise regularly or practice any sport in your free time (yes, no)". We also inquired into whether the pregnancy had been planned (yes, no), assuming that, this variable could interfere with duration of breastfeeding, as shown by a review article 25 and possibly also in weight retention via food, physical activity or other behavioral factors.

Considering that diet and exercise can influence maternal weight retention, a variable indicating the quality of maternal nutrition was created to adjust the analyses for these factors, if necessary: the healthy diet score, assessed at six and twelve months post-delivery (EAS-6 and EAS-12, respectively). This score was constructed by adding points given to the weekly frequency of consumption of fruit, vegetables, and beans. Higher sums tend to indicate more adequate diets, varying from zero to three points (healthier $=3$ ). An indicator score for unhealthy diets was also constructed from a sum of the points given to the frequency of consumption of soft drinks, sweets, and substitution of food for snacks. Larger sums tend to indicate less healthy diets, with a variation from zero to three points (less healthy $=3) .{ }^{26}$

The mean values and descriptive statistics of the mothers' postpartum weight retention for the cohort and according to the infants' breastfeeding situation (EBF and $\mathrm{BF}$ ) at different ages were calculated and compared, at 3 (BF3 and EBF3), 6 (BF6 and EBF6), 9 (BF9 and EBF9) and 12 (BF12) months postpartum, using Student's $t$-test for this and adopting $p<0.05$ as the level of statistical significance.

As mentioned above, only weight retention values at six and twelve months postpartum were used as outcomes when investigating the effect of 
$\mathrm{EBF}$ and $\mathrm{BF}$ duration. When analyzing the effect of $\mathrm{EBF}$ and $\mathrm{BF}$ duration on maternal weight retention at six months postpartum, the maximum duration period for both was considered to be 180 days; whereas at 12 months, the maximum duration period for $\mathrm{EBF}$ and $\mathrm{BF}$ was 12 months or 366 days.

The association between the duration of exclusive breastfeeding and breastfeeding with maternal weight retention at six and twelve months postpartum was assessed using linear regression models adjusted for potential confounders, identified as variables in crude or univariate analyses that presented statistical significance at the $p \leq 0.10$. In adjusted analyses, the relation were considered significant if $p<0.05$. The regression models' non-standardized coefficients (b) were used to assess the magnitude of the effects. The analyses were performed with the IBM SPSS software, v20.

The normality of the residuals in the 4 multiple models performed was assessed by the Shapiro-Wilk test, but it was not confirmed; homoscedasticity was evaluated by plotting the residuals versus predictors and was confirmed. Despite the lack of normality of the residuals, the variances had homoscedasticity, contributing to the quality of the estimation process and the significance test of the parameters of the adjusted models. The alternatives existing in the statistical literature to circumvent the absence of normal residuals would not bring gains for the epidemiological interpretation of the results.

\section{Results}

The cohort began with 641 mother-infant pairs and there were losses over the follow-up period due to mothers not being located or refused to continue taking part in the study, and had missing or inconsistent maternal weight data. At 3 months postpartum, valid weight retention data were obtained of 510 mothers, 485 at 6,498 at 9 and 507 at 12 months postpartum. Details of the losses and their reasons are shown in Figure 1, in which it can be noted that inconsistent maternal weight values (pre-gestational or measured weight) throughout the first postpartum year were the main reasons for the losses. Comparing the mother-infant pairs that remained in the study up to six and twelve months with the losses, there were no significant differences regarding their socioeconomic and demographic characteristics (data not shown in Table).

The mothers' ( $\mathrm{n}=641)$ and infants' characteristics at baseline are shown in Table 1. There is a predominance of adult mothers ( $\geq 19$ years old), with nine years or more of schooling $(82.9 \%)$, and most were white $(62.1 \%)$; the vast majority $(87.8 \%)$ lived with a partner. About half (49.1\%) were primiparous, $52.4 \%$ underwent cesarean section, and $52.4 \%$ did not plan their pregnancy. One fifth of the mothers had pre-gestational obesity (20.3\%) and $43.9 \%$ had excessive weight gain during pregnancy. Their average height was $1.62 \mathrm{~m}$ (SD $0.07 \mathrm{~m})$, with a minimum of $1.45 \mathrm{~m}$ and a maximum of $1.83 \mathrm{~m}$. Most newborns were born at term $(94.1 \%)$ with adequate weight $(93.8 \% \geq 2,500 \mathrm{~g})$.

The quality of maternal nutrition and the frequency of mothers who exercised regularly had a negative evolution: the average healthy diet score was 1.77 (SD 0.67) and the unhealthy diet score was $1.22(0.56)$ at six months postpartum; at twelve months, the average healthy score dropped to 0.59 (SD 0.37) while the unhealthy score increased to 1.17 (SD 0.61). As for physical exercise, at six months postpartum, $87.7 \%$ of the women stated that they had not regularly exercised or practiced sports in the last trimester, a value that rose to $91.4 \%$ at twelve months (Table 1).

The mean maternal weight retention was 1.69 $\mathrm{kg}, 1.79 \mathrm{~kg}, 1.75 \mathrm{~kg}$, and $1.69 \mathrm{~kg}$, at 3, 6, 9 and 12 months postpartum respectively, with median values of $1.80 \mathrm{~kg} ; 1.80 \mathrm{~kg} ; 1.50 \mathrm{Kg}$, and $1.20 \mathrm{Kg}$. There was a wide variation in weight retention and about a quarter of the mothers showed retention equal to or greater than $5 \mathrm{~kg}$ in these postpartum periods (data not shown in the table).

Table 2 shows the mean values, respective standard deviations and $95 \%$ confidence intervals of maternal weight retention according to infants' breastfeeding situation at different ages: at 3, 6, 9 and 12 months. Lower mean values are observed in mothers of breastfeeding infants at all evaluated ages. However, the differences were only statistically significant when the infants had EBF at three months and BF at six months for average weight retention at 6 and 12 months postpartum. It is also noted that the means did not change significantly after 3 months postpartum and that there was great variability during all assessedperiods.

The results of the crude analyses that investigated the association between the EBF and BF duration and covariates with the outcomes are shown in Table 3. The EBF and BF duration was negatively associated with maternal weight retention 6 months after childbirth. Potential confounding factors $(p \leq 0.10)$ were identified for this association: adequacy of gestational weight gain $(p<0.001)$, pregestational BMI $(p<0.001)$, planned pregnancy $(p=0.105)$ and parity $(p=0.091)$. In the case of weight retention at 12 months postpartum, the following 
Figure 1

Flowchart on the cohort according to the follow-up moment. Botucatu, SP CLaB Study, 2015/2017.

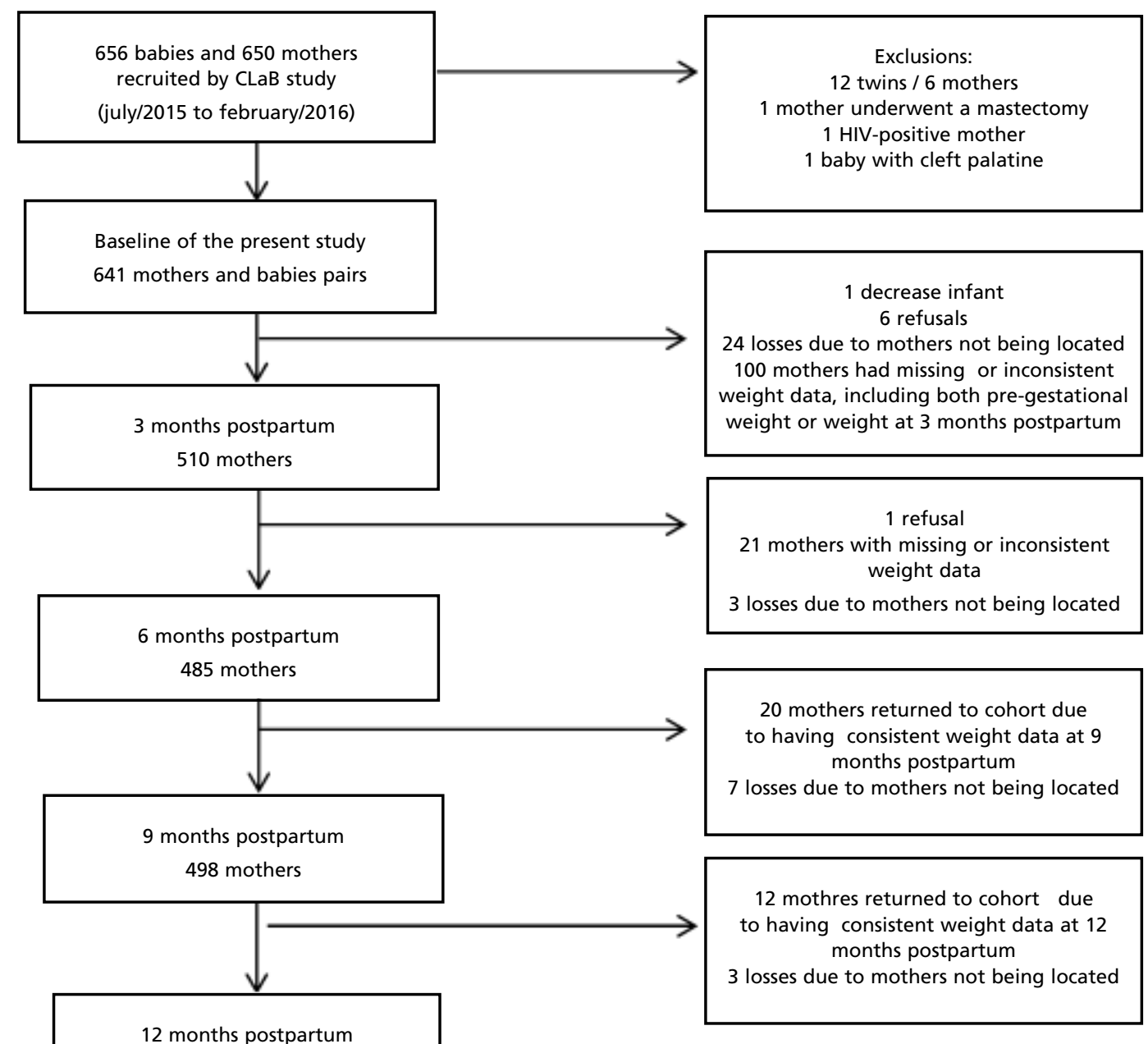

possible confounding factors were selected: planned pregnancy $(p=0.042)$, adequacy of gestational weight gain $(p=0.009)$, pre-gestational BMI ( $p=0.011)$, paid work outside the home $(p=0.083)$ and type of delivery $(p=0.071)$. These variables were inserted in the multiple models.

According to the results of the multiple regression models adjusted by the confounders identified by the crude analyses, EBF duration influenced maternal weight retention, with a mean effect of $-11 \mathrm{~g}$ and $-16 \mathrm{~g}$ for each additional day of EBF on maternal weight retention at 6 and 12 months postpartum, respectively. Each additional day of $\mathrm{BF}$ (considering a maximum of 180 days) reduced maternal weight retention by an average of 12 grams at six months postpartum. The effect on the duration of total breastfeeding (considering a maximum of 366 days) on weight retention at 12 months after childbirth was smaller: an average reduction of 5 grams per day of breastfeeding (Table 4).

\section{Discussion}

The present study examines an issue that is still inconclusive in the literature: the association between breastfeeding and postpartum weight retention. The results indicate that mothers who breastfed exclusively for a longer time had lower weight retention six and twelve months after childbirth. When analyzing total breastfeeding duration (supplemented or not), there was also a negative influence on weight retention at six and twelve months post- 


\section{Table 1}

Sociodemographic, gestational, nutritional and behavioral characteristics of mothers and infants at birth ( $\mathrm{N}=641)$ baseline. CLaB study. Botucatu, 2015-2017.

\begin{tabular}{|c|c|c|}
\hline Variables & $\mathbf{N}$ & $\%$ \\
\hline \multicolumn{3}{|l|}{ Age (years) } \\
\hline$\leq 19$ & 82 & 12.9 \\
\hline 20 to 34 & 456 & 71.5 \\
\hline$\geq 35$ & 100 & 15.6 \\
\hline \multicolumn{3}{|c|}{ Schooling (complete years of study) } \\
\hline$\leq 8$ & 109 & 17.1 \\
\hline 9 to 11 & 407 & 63.8 \\
\hline$\geq 12$ & 122 & 19.1 \\
\hline \multicolumn{3}{|l|}{ Skin color (self-reported) } \\
\hline White & 396 & 62.1 \\
\hline Non-white & 242 & 37.9 \\
\hline \multicolumn{3}{|l|}{ Parity } \\
\hline Primiparous & 313 & 49.1 \\
\hline Multiparous & 325 & 50.9 \\
\hline \multicolumn{3}{|l|}{ Paid work outside home } \\
\hline Yes & 365 & 56.9 \\
\hline No & 276 & 43.1 \\
\hline \multicolumn{3}{|c|}{ Mother lives with a partner } \\
\hline Yes & 560 & 87.8 \\
\hline No & 78 & 12.2 \\
\hline \multicolumn{3}{|l|}{ Type of childbirth } \\
\hline Vaginal birth & 304 & 47.6 \\
\hline Cesarean section & 334 & 52.4 \\
\hline \multicolumn{3}{|c|}{ Pre-gestational nutritional status } \\
\hline Normal & 279 & 47.3 \\
\hline Low weight & 23 & 3.9 \\
\hline Overweight & 168 & 28.5 \\
\hline Obesity & 120 & 20.3 \\
\hline \multicolumn{3}{|c|}{ Adequacy of gestational weight gain according to IOM (2009) } \\
\hline Adequate & 202 & 36.0 \\
\hline Insufficient & 113 & 20,1 \\
\hline Excessive & 246 & 43.9 \\
\hline \multicolumn{3}{|l|}{ Planned pregnancy } \\
\hline Yes & 304 & 47.6 \\
\hline No & 334 & 52.4 \\
\hline \multicolumn{3}{|c|}{ Situation of the infant at birth } \\
\hline Born at term & 587 & 94.1 \\
\hline Preterm & 51 & 5.7 \\
\hline \multicolumn{3}{|l|}{ Birth weight } \\
\hline Adequate $(\geq 2500 \mathrm{~g})$ & 595 & 93.8 \\
\hline Low weight $(<2500 \mathrm{~g})$ & 39 & 6.2 \\
\hline \multicolumn{3}{|c|}{ Regular physical exercises at 6 months postpartum } \\
\hline Yes & 78.9 & 12.3 \\
\hline No & 562.1 & 87.7 \\
\hline \multicolumn{3}{|c|}{ Regular physical exercises at 12 months postpartum } \\
\hline Yes & 56.2 & 8.6 \\
\hline No & 584.8 & 91.4 \\
\hline
\end{tabular}

$\mathrm{IOM}=$ Institute of Medicine.

continue 
Sociodemographic, gestational, nutritional and behavioral characteristics of mothers and infants at birth ( $N=641)$ baseline. CLaB study. Botucatu, 2015-2017.

\begin{tabular}{lc}
\hline Variables & $\overline{\mathbf{X}} \pm$ SD \\
\hline Maternal height (meters) & $1.62 \pm 0.07$ \\
Maternal healthy food score (0-3) & $1.77 \pm 0.67$ \\
At 6 months postpartum & $0.59 \pm 0.37$ \\
At 12 months postpartum & \\
Maternal unhealthy food score (0-3) & $1.22 \pm 0.56$ \\
At 6 months postpartum & $1.17 \pm 0.61$ \\
At 12 months postpartum & \\
\hline
\end{tabular}

Table 2

Postpartum maternal weight retention $(\mathrm{Kg})$ according to infants' breastfeeding situation at different ages. CLaB Study, Botucatu, 20152017.

\begin{tabular}{|c|c|c|c|c|c|c|c|c|c|}
\hline \multirow[t]{2}{*}{$\begin{array}{l}\text { Type of breastfeeding/ } \\
\text { age }\end{array}$} & \multicolumn{3}{|c|}{$\begin{array}{l}\text { Weight retention at } 6 \text { months } \\
\text { postpartum }\end{array}$} & \multicolumn{3}{|c|}{$\begin{array}{c}\text { Weight retention at } 9 \text { months } \\
\text { postpartum }\end{array}$} & \multicolumn{3}{|c|}{$\begin{array}{c}\text { Weight retention at } 12 \text { months } \\
\text { postpartum }\end{array}$} \\
\hline & $\bar{X} \pm S D$ & $\mathrm{Cl} 195 \%$ & $p$ & $\bar{X} \pm S D$ & $\mathrm{Cl} 95 \%$ & $p$ & $\bar{X} \pm S D$ & $\mathrm{Cl} 195 \%$ & $p$ \\
\hline BF $3 m$ & & & 0.116 & $1.73 \pm 5.95$ & $1.16-2.30$ & 0.726 & $1.49 \pm 6.41$ & $0.88-2.09$ & 0.221 \\
\hline Yes & $1.60 \pm 5.56$ & $1.06-2.14$ & & $1.92 \pm 5.80$ & $0.57-3.27$ & & $2.43 \pm 7.90$ & $0.55-4.31$ & \\
\hline No & $2.79 \pm 5.24$ & $1.50-4.08$ & & & & & & & \\
\hline BF $6 \mathrm{~m}$ & & & 0.036 & & & 0.667 & & & 0.278 \\
\hline Yes & $1.39 \pm 5.60$ & $0.78-2.00$ & & $1.63 \pm 6.00$ & $0.98-2.27$ & & $1.41 \pm 6.30$ & $0.73-2.08$ & \\
\hline No & $2.55 \pm 5.30$ & $1.70-3.40$ & & $1.96 \pm 5.54$ & $1.09-2.82$ & & $2.06 \pm 7.28$ & $0.93-3.18$ & \\
\hline BF 9m & & & & & & 0.972 & & & 0.255 \\
\hline Yes & - & - & & $1.41 \pm 6.00$ & $0.66-2.16$ & & $1.33 \pm 6.39$ & $0.55-2.12$ & \\
\hline No & - & - & & $2.09 \pm 5.83$ & $1.36-2.81$ & & $2.01 \pm 7.02$ & $1.14-2.89$ & \\
\hline BF $12 \mathrm{~m}$ & & & & & & & & & 0.164 \\
\hline Yes & - & - & & - & - & & $1.14 \pm 6.42$ & $0.25-2.04$ & \\
\hline No & - & - & & - & - & & $1.93 \pm 6.76$ & $1.16-2.7$ & \\
\hline EBF $3 m$ & & & 0.004 & & & 0.668 & & & 0.001 \\
\hline Yes & $0.97 \pm 5.41$ & $0.26-1.68$ & & $1.05 \pm 5.88$ & $0.30-1.80$ & & $0.52 \pm 5.86$ & $-0.22-1.27$ & \\
\hline No & $2.49 \pm 5.54$ & $1.79-3.18$ & & $2.33 \pm 5.89$ & $1.61-3.06$ & & $2.61 \pm 7.13$ & $1.74-3.48$ & \\
\hline EBF $6 \mathrm{~m}$ & & & 0.541 & & & 0.990 & & & 0.503 \\
\hline Yes & $0.85 \pm 5.65$ & $-2.57-4.26$ & & $0.95 \pm 5.36$ & $-2.01-3.92$ & & $0.52 \pm 5.86$ & $-2.72-3.76$ & \\
\hline No & $1.79 \pm 5.53$ & $1.29-2.30$ & & $1.76 \pm 5.87$ & $1.23-2.29$ & & $1.65 \pm 6.66$ & $1.05-2.24$ & \\
\hline
\end{tabular}

$\mathrm{BF}=$ total breastfeeding; $\mathrm{EBF}=$ exclusive breastfeeding; $p<0.05$. 
Table 3

Results of crude linear regression analyses that assessed the association between exposure variables and covariates with maternal weight retention at 6 and 12 months postpartum. CLaB Study, Botucatu, 2015-2017.

\begin{tabular}{|c|c|c|c|c|c|c|}
\hline \multirow[t]{2}{*}{ Variables } & \multicolumn{3}{|c|}{$\begin{array}{l}\text { Weight retention at } 6 \text { months } \\
\text { postpartum }\end{array}$} & \multicolumn{3}{|c|}{$\begin{array}{l}\text { Weight retention at } 12 \text { months } \\
\text { postpartum }\end{array}$} \\
\hline & $\beta$ & $\mathrm{Cl} 95 \%$ & $p$ & $\beta$ & $\mathrm{Cl} 195 \%$ & $p$ \\
\hline EBF Duration (days) & -0.012 & $-0.020 ;-0.003$ & 0.007 & -0.016 & $-0.026 ;-0.006$ & 0.001 \\
\hline BF Duration (days) & -0.006 & $-0.012 ; 0.001$ & 0.079 & -0.001 & $-0.009 ; 0.007$ & 0.791 \\
\hline Mother's age (years) & 0.159 & $-0.479 ; 0.796$ & 0.625 & -0.162 & $-0.921 ; 0.596$ & 0.674 \\
\hline Maternal schooling (completed years) & -0.355 & $-1.174 ; 0.465$ & 0.396 & -0.239 & $-1.218 ; 0.739$ & 0.631 \\
\hline Paid work outside home (yes, no) & -0.265 & $-1.263 ; 0.734$ & 0.603 & -1.046 & $-2.231 ; 0.139$ & 0.083 \\
\hline Planned pregnancy (yes, no) & 0.813 & $-0.171 ; 1.798$ & 0.105 & 1.214 & $0.046 ; 2.382$ & 0.042 \\
\hline Lives with a partner (yes, no) & -0.512 & $-1.961 ; 0.936$ & -0.487 & 1.182 & $-0.591 ; 2.955$ & 0.191 \\
\hline Healthy food score $(0-3)$ & -0.236 & $-1.015 ; 0.543$ & 0.552 & -0.925 & $-2.546 ; 0.696$ & 0.263 \\
\hline \multicolumn{7}{|l|}{ Adequacy of gestational weight gain } \\
\hline (adequate, insufficient, excessive) & 1.126 & $0.557 ; 1.696$ & 0.000 & 0.892 & $0.219 ; 1.565$ & 0.009 \\
\hline \multicolumn{7}{|l|}{ Classification of pre-gestational BMI } \\
\hline (normal weight, underweight, overweight, obese) & -0.929 & $-1.328 ;-0.531$ & 0.000 & -0.615 & $-1.086 ;-0.144$ & 0.011 \\
\hline \multicolumn{7}{|l|}{ Regular physical exercises at six months } \\
\hline postpartum (yes, no) & -0.809 & $-2.318 ; 0.701$ & 0.293 & 1.017 & $-1.042 ; 3.076$ & 0.332 \\
\hline Type of childbirth (vaginal or cesarean) & 0.093 & $-0.895 ; 1.080$ & 0.854 & -1.077 & $-2.246 ; 0.092$ & 0.071 \\
\hline Parity (primiparous or multiparous) & -0.850 & $-1.836 ; 0.135$ & 0.091 & -0.056 & $-1.228 ; 1.116$ & 0.925 \\
\hline Skin color (white/non-white) & -0.386 & $-1.415 ; 0.642$ & 0.461 & 0.252 & $-0.958 ; 1.463$ & 0.682 \\
\hline
\end{tabular}

$\mathrm{EBF}=$ exclusive breastfeeding; $\mathrm{BF}=$ total breastfeeding; $\beta=$ linear regression non-standardized coefficient; $\mathrm{BMI}=$ body mass index; $\mathrm{CLaB}=$ B otucatu Infant Cohort S tudy.

Table 4

Results on multiple linear regression models between exclusive breastfeeding (EBF) and total breastfeeding (BF) duration and weight retention at six and twelve months postpartum. CLaB Study, Botucatu, 2015-2017.

\begin{tabular}{|c|c|c|c|c|c|c|}
\hline \multirow[t]{2}{*}{ Type of breastfeeding } & \multicolumn{3}{|c|}{$\begin{array}{l}\text { Weight retention at } 6 \text { months } \\
\text { postpartum }\end{array}$} & \multicolumn{3}{|c|}{$\begin{array}{l}\text { Weight retention at } 12 \text { months } \\
\text { postpartum }\end{array}$} \\
\hline & $\beta$ & $\mathrm{Cl} 95 \%$ & $p$ & $\beta$ & $\mathrm{Cl} 95 \%$ & $p$ \\
\hline EBF (days) & 0.011 * & $-0.019 ;-0.003$ & 0.01 & $0.016 * *$ & $-0.026 ;-0.007$ & 0.001 \\
\hline BF (days) & $0.012 *$ & $-0.021 ;-0.002$ & 0.01 & $0.005 * *$ & $-0.009 ; 0.0001$ & 0.05 \\
\hline
\end{tabular}

* Adjusted for the following covariates: parity, adequacy of gestational weight gain, BMI/pre-gestational classification and planned pregnancy; ** Adjusted for the following covariates: maternal work status, adequacy of gestational weight gain, BMI/pre-gestational classification, planned pregnancy and type of childbirth.

partum, although of a lesser magnitude. These results support include lower postpartum weight retention in the list of benefits of breastfeeding for maternal and child health and are in line with previous studies that had already detected this effect. 12,13

Previous studies that had not detected this association failed, possibly because the sample was small10 or because they collected the information retrospectively, 14 which may have led to errors in the estimates of breastfeeding duration and consequently in assessingits effects.

Explaining the influence of breastfeeding on postpartum retention has been a challenge for researchers. The postulated mechanisms are: 1) the increase in energy expenditure since lactation consumes around 450 to $700 \mathrm{Kcal} /$ day, and 2) metabolism and appetite regulation during lactation and after its cessation. The first path could explain the negative influence of breastfeeding while it was in force and would also explain the greater effect of $\mathrm{EBF}$ in relation to $\mathrm{BF}$. This mechanism was ques- 
tioned by Danish researchers 27 who did not identify any effect on the duration of breastfeeding on women's weight retention who presented excessive gestational weight gain. However, in our study, the effect of a longer duration of breastfeeding on weight retention was significant even when adjusted for gestational weight gain and pre-gestational BMI, regardless of their nutritional status and weight gain during pregnancy, indicating that it has a positive effect on obesity prevention.

Another mechanism that could explain the longterm effects of EBF duration on retention at twelve months postpartum is that breastfeeding could have an influence on hormones that regulate a woman's metabolism and satiety and that such effects would remain even after the cessation of breastfeeding. In this sense, the results of only two studies we found are conflicting. Stuebe et al. 28 found elevated levels of ghrelin and YY peptides three years after childbirth in women who had breastfed exclusively for six months and also in those who had breastfed (exclusively or not) for at least one year. These adipokines have different roles in the human body, such as regulating appetite, the immune system, energy balance and among others. Various hormones, including ghrelin (an appetite stimulant) and YY peptides (an anorectic), could be involved in regulating the appetite and metabolism of nursing mothers in ways that reduce weight retention. The other study, developed by Larson-Meyer et al.,29 did not detect differences in the levels of these hormones between breastfeeding and non-breastfeeding mothers in six months of postpartum follow-up, contradicting the hypothesis and leaving the question still open for further studies.

The mean values of weight retention that we obtained were lower than those reported by previous Brazilian studies. In a study in the State of Rio de Janeiro, the average retention was 3.4 and $3.1 \mathrm{~kg}$ at 6 and 9 months postpartum, respectively 6 ; in Bahia State, 30 the mean retention at 12 months postpartum was $-3.157 \mathrm{~kg}$. Differences in the population profile of the cohorts on the aforementioned studies and the one carried out in Botucatu can explain such differences: our cohort included mothers and infants who were users of both public and private services and had a population base, while the cohort in Rio de Janeiro included only users of public primary health care services and the cohort studied in Bahia was formed predominantly of poor women from rural areas, where the share of overweight and obese women was very low, which may explain the negative average on weight retention. Due to differences in socioeconomic context and nutritional profile, comparability between different national studies is very limited, indicating the necessity for a study with a representative sample of the Brazilian population so that the magnitude of postpartum weight retention is established and regional and socioeconomic contrasts are better understood.

A secondary finding in our study which deserves to be mentioned and may be of interest to professionals linked to maternal and child health is that there was a very low percentage of mothers who exercised regularly, even when the infant had already completed twelve months of age. This may explain why we did not detect an association between physical exercise and postpartum weight retention in the crude analyses. It is also worth mentioning that there was no association between the food quality score and weight retention. However, the diet and exercise related variables that we analyzed were measured with little detail. Therefore, there is another possibility to explain the lack of influence of these variables: limited information, as it was not possible to assess the exercise level of the mothers or their energy consumption, both of which would be more appropriate to measure.

Other limitations of our study that deserve to be taken in consideration are the size of our sample, which was defined for the purposes of the matrix study $(\mathrm{CLaB})$ and not for the question of the present study, and the fact that maternal weight was measured at a single time on each assessment. As for the effects of breastfeeding on maternal weight retention, larger samples could lead to more accurate effect estimates, with smaller confidence intervals. In the second case, when the comparison with the pre-gestational weight and the weight measured in the Clinica do Bebê led to the suspicion about the validity of subsequent weights, we chose to disregard the measure, which led to losses in the number of mothers assessed at each point in the study. However, it increases the quality of the data that were actually analyzed.

The prospective design and the quality of information on the duration of exclusive breastfeeding and breastfeeding both favor the validity of our results, as frequent interviews were carried out with mothers throughout the infant's first year of life, through a long questionnaire that asked about consumption of 48 types of food, thus avoiding memory bias.

In summary, the present study is in line with the previous ones 13,15 which had identified a protective role for breastfeeding on maternal weight retention but disagrees with studies that did not observe this 
role. 14 Therefore, it contributes to consolidating knowledge about the inverse association between breastfeeding duration and weight retention.

It is common for mothers to retain weight postpartum in the context of the study, and the average retained weight $(1.69 \mathrm{~kg})$ is high. The duration of exclusive and total breastfeeding had a negative influence on this retention, regardless of gestational weight gain, the woman's nutritional status at the beginning of pregnancy and other factors controlled by the potential to confuse the investigated associations. The magnitude of the effect on breastfeeding and exclusive breastfeeding duration was small but relevant: at six and twelve months postpartum, respectively, $-11 \mathrm{~g}$ and $-16 \mathrm{~g}$ of weight retained each day plus exclusive breastfeeding and $-12 \mathrm{~g}$ and $-5 \mathrm{~g}$ of maternal weight retained each day more than breastfeeding, supplemented or not.

\section{References}

1. Poston L, Caleyachetty R, Cnattingius S, Corvalán C, Uauy R, Herring S, Gillman MW. Preconceptional and maternal obesity: epidemiology and health consequences. Lancet Diabetes Endocrinol. 2016; 1025: 36.

2. Mason KE, Pearce N, Cummins S. Associations between fast food and physical activity environments and adiposity in mid-life: cross-sectional, observational evidence from UK Biobank. Lancet Public Health. 2018; 24-33.

3. Maziero CCS, Jaime PC, Duran AC. A influência dos locais de refeição e de aquisição de alimentos no consumo de frutas e hortaliças por adultos no município de São Paulo. Rev Bras Epidemiol. 2017; 611-23.

4. Ferreira RAB, Benicio, MHDA. Obesidade em mulheres brasileiras: associação com paridade e nível socioeconômico. Rev. Panam Salud Publica. 2015; 4: 337-42.

5. Kwon E J, Kim YJ. What is fetal programming? A lifetime health is under the control of in utero health. Obstet Gynecol. 2017.60: 506-19.

6. Kac G, Benicio MHD, Melendez GV, Valente JG, Struchiner CJ. Breastfeeding and postpartum weight retention in a cohort of Brazilian women. AmJ Clin Nutr. 2004;79: 48793.

7. Villamor E, Cnattingius S. Interpregnancy weight change and risk of adverse pregnancy outcomes: a population based study. Lancet.2006; 368 (9542):1164-702006.

8. Rebelo F, Castro MBT, Dutra CL, Schlussel MM, Kac G. Fatores associados à retenção de peso pós-parto em uma coorte de mulheres, 2005-2007. Rev Bras Saúde Mater Infant. 2010;10 (2): 219-27.

9. Lacerda MEA, Leal MC. Fatores associados com a retenção e o ganho de peso pós-parto: uma revisão sistemática. Rev Bras Epidemiol. 2004;7: 187-200.

10. Forte CC, Bernardij R, Goldani MZB. Relação entre a

\section{Acknowledgments}

We thank the São Paulo Research Foundation (FAPESP) for its financial support.

\section{Authors' contribution}

Carvalhaes MABL, Gomes CB and Alves MS formulated the study, performed analysis, interpretation and wrote the article. Almeida MAM performed data collection, statistical analysis and writing of the article. Parada CMGL coordinated the study, data interpretation and writing of the manuscript. Ferrari AP collaborated with the interpretation of the results and revision of the manuscript. All authors approved the final version of the manuscript. retenção de peso nos primeiros três meses pós-parto com ganho de peso e ingestão alimentar durante a gestação. Rev Bras Saúde Mater Infant. 2015;15 (3): 279-87.

11. Tussing-Humphreys LM, Thomson JL, Hemphill NO, Goodman MH, Landry AS. Maternal weight in the postpartum: results from the Delta Healthy Sprouts trial. Mater Health Neonatol Perinatol. 2017; $3: 20-31$

12. Zanotti J, Capp E, Wender MCO. Factors associated with postpartum weight retention in a Brazilian cohort. Rev Bras Ginecol Obstet. 2015; 37: 164-71.

13. Chagas, DC, Silva AAM, Ribeiro CC, Batista RFL, Britto e Alves MTSS. Efeitos do ganho de peso gestacional e do aleitamento materno na retenção de peso pós-parto em mulheres da coorte BRISA Cad Saúde Pública. 2017; 33: e00007916.

14. Potter S, Hannum S, Mcfarlin B, Essex-sorlie, D, Campbell E, Trupin S. Does infant feeding method influence maternal postpartum weight loss? J Am Diet Assoc. 1991; 91: 441-6.

15. Shu-Kay NG, Cameron CM, Hills AP, McClure RJ, Scuffham PA. Socioeconomic disparities in pre-pregnancy BMI and impact on maternal and neonatal outcomes and postpartum weight retention: the EFHL longitudinal birth cohort study. BMC Pregnancy Childbirth. 2014; 14:314-29.

16. SEADE (Fundação Sistema Estadual de Análise de Dados).[acesso em 01 de março de 2019] Brasília: SEADE; 2015. Disponível em: http://www.seade.gov.br/.

17. Prefeitura municipal de Botucatu, 2012 [acesso em 25 de junho de 2019]. Disponível em: http://www.botucatu.sp.gov.br

18. Brasil. Ministério da Saúde. Secretaria de Atenção à Saúde. Departamento de Atenção Básica. Orientações para coleta e análise de dados antropométricos em serviços de saúde: Normas Técnica do Sistema de Vigilância Alimentar e Nutricional SISVANY̌ Ministério da Saúde. Secretaria de Atenção à Saúde. Departamento de Atenção Básica. Brasília, DF; 2011. 76:11. 
19. Kac G, Velásquez-Meléndez G. Ganho de peso gestacional e macrossomia em uma coorte de mães e filhos. J Pediatr. (Rio J). 2005; 47-53.

20. Nucci LB, Schmidt MI, Duncan BB, Fuchs SC, Fleck ET, Santos MMB. Nutritional status of pregnant women: prevalence and associated pregnancy outcomes. Rev Saúde Pública. 2001; 35: 502-7.

21. Brasil. Ministério da Saúde. Secretaria de Atenção à Saúde. Departamento de Atenção Básica. Saúde da criança: nutrição infantil: aleitamento materno e alimentação complementar / Ministério da Saúde, Secretaria de Atenção à Saúde, Departamento de Atenção Básica. Brasília, DF; 2009.

22. Brasil, Ministério da Saúde. Secretaria da Atenção à Saúde. Departamento de Atenção Básica. Orientações para avaliação de marcadores de consumo alimentar na atenção básica (recurso eletrônico). Brasília: Ministério da Saúde, $2015 ; 33 p$.

23. Parada CMGL, Carvalhaes MABL, Jamas MT. Práticas de alimentação complementar em crianças no primeiro ano de vida. Rev Latino-am Enferm. 2007; 15 (2): 282-9.

24. Institute of Medicine and National Research Council (US) Committee to Reexamine IOM Pregnancy Weight Guidelines; Rasmussen KM,Yaktine AL, editors. Weight gain during pregnancy: reexamining the guidelines. Washington: National Academy Press; 2009.
25. Rocha AF, Gomes KRO, Rodrigues MTP, Mascarenhas MDM, Freire ALL. Intenção de engravidar e amamentação: revisão integrativa. Rev Bras Promoç Saúde. 2018; 21 (2): $1-10$

26. Figueiredo, ICR, Jaime PC, Monteiro CA. Fatores associados ao consumo de frutas, legumes e verduras em adultos da cidade de São Paulo. Rev. Saúde Pública 2008; 42 (5): $777-85$.

27. Baker JL1, Gamborg M, Heitmann BL, Lissner L, Sorensen TI, Rasmussen KM. Breastfeeding reduces postpartum weight retention. Am J Clin Nutr.2008; 88 (6):1543-51.

28. Stuebe, AM, Mantzoros C, Kleinman K, Gillman MW, Rifas-shiman S, Gunderson EP. Duration of lactation and maternal adipokines at 3 years postpartum. Diabetes. 2011; 60: $1277-85$

29. Larson-Meyer DE, Ravussin E, Heibronn L, DeJonge L. Ghrelin and peptide $\mathrm{YY}$ in postpartum lactanting and nonlactanting women. Am J Clin Nutr. 2010: 366-72.

30. Silva, M C, Oliveira A M P, Magalhães LO; Fonseca, NS; Santana, M LP, Góes Neto E A, Cruz TRP. Determinants of postpartum weight variation in a cohort of adult woman: a hierarchical approach. Nutr Hosp. 2013; 28 (3): 660-70.

Received on January 3, 2019

Final version presented on July 25, 2019

Approved on December 27, 2019 